\title{
Spectrum of clinical features and neuroimaging findings in acute cerebral infarction patients with unusual ipsilateral motor impairment- a series of 22 cases
}

\author{
Zhe-Ren Tan, Chen Zhang and Fa-Fa Tian *i]
}

\begin{abstract}
Background: Cerebral infarction occurs when the arteries to brain are obstructed, and motor impairment contralateral to responsible lesion is commonly recognized. Few studies have profiled the characteristics of cases with ipsilateral motor impairment. We sought to characterize clinical features of patients with motor dysfunction caused by ipsilateral ischemic stroke.

Methods: We retrieved and analyzed the medical data for patients with ipsilateral cerebral infarction. Patients were regarded as having ipsilateral cerebral infarction if motor impairment is ipsilateral to recent stroke lesions.

Results: Only 22 patients with unusual ipsilateral cerebral infarction were included in this study. Ipsilateral limb paralysis was observed in all cases, and one case showed central facioplegia. Majority of patients with limb paralysis $(90.9 \%, 20 / 22)$ presented with mild muscle strength deficits (MRC grading of 4 or more). Most of the patients $(72.7 \%, 16 / 22)$ had a past history of stroke, and previous strokes were contralateral to the side of the recent stroke in 14 out of 16 patients (87.5\%). No history of stroke or cerebral injury was identified in seven patients. With aspect of MRI findings, recent infarct lesions of all cases were located along the corticospinal tract.

Conclusions: History of stroke plays an important role in the pathogenesis of ipsilateral motor impairment, and cortical reorganization in the unaffected hemisphere may contribute to the compensation of motor function after stroke. Besides that, some cases with first stroke may be due to impairment of ipsilateral uncrossed corticospinal fibers.
\end{abstract}

Keywords: Ipsilateral stroke, Cerebral infarction, Cerebrovascular disease, Neuroimaging, Hemiparesis

\section{Background}

Previous neuroanatomic studies have firmly demonstrated that the primary motor cortex predominantly innervates the contralateral half of the body. Almost all patients with supratentorial stroke involving the pyramidal tract exhibit contralateral motor dysfunction. Conversely, more and more cases of ipsilateral stoke or deterioration of hemiparesis ipsilateral to the cerebral injury are reported [1-4], One previous

\footnotetext{
* Correspondence: xysntff@sina.com; tanzheren@126.com

Department of Neurology, Xiangya Hospital, Central South University, 87 Xiangya Road, Changsha 410008, China
}

study focused on ipsilateral hemiparesis in ischemic stroke patients found a high proportion of history of stroke contralateral to the recent stroke in cases of ipsilateral hemiparesis [5], which indicating the need to investigate unusual ipsilateral stroke for exploring the mechanism of post-stroke compensatory motor function, such as the enhanced pyramidal tract $[1,6]$. increased cerebral blood flow $[7,8]$ and increased activation of motor regions $[9,10]$ in unaffected hemisphere after stroke. However, severe case reports of stroke leading to ipsilateral motor weakness are published but there is no study that

(c) The Author(s). 2019 Open Access This article is distributed under the terms of the Creative Commons Attribution 4.0 International License (http://creativecommons.org/licenses/by/4.0/), which permits unrestricted use, distribution, and reproduction in any medium, provided you give appropriate credit to the original author(s) and the source, provide a link to the Creative Commons license, and indicate if changes were made. The Creative Commons Public Domain Dedication waiver (http://creativecommons.org/publicdomain/zero/1.0/) applies to the data made available in this article, unless otherwise stated. 
summarizes the clinical characteristics and neuroimaging findings of cerebral infarction patients with unusual ipsilateral motor impairment of limb and cranial nerves.

In present study, we sought to investigate and characterize the clinical features and magnetic resonance imaging (MRI) findings in cerebral infarction patients with ipsilateral motor impairment.

\section{Methods}

We retrieved the medical data for ipsilateral cerebral infarction patients treated between Jan 2011 and June 2018 in the Department of Neurology, Xiangya Hospital, Central South University, Changsha, China.

Patients were diagnosed as ipsilateral cerebral infarct and included in present study if they satisfied the following criteria: (1) For each case, the diagnosis of recent cerebral infarct was confirmed by complete clinical assessment and MRI. (2) Patients who experienced confirmed motor impairment due to the recent cerebral infarct. (3) The responsible lesions of patients with limb paralysis were located above the decussation of pyramid and ipsilateral to their motor impairment. (4) The responsible lesions of patients with central cranial nerve paralysis were located above the brainstem and ipsilateral to their motor impairment. (5) Patients who underwent MRI and MRI radiographs of all patients show recent hyperintense lesions on T2-weighted images and diffusion-weighted imaging (DWI) which is ipsilateral to recent motor dysfunction. (6) Medical data are complete and available. (7) Informed consent was obtained from patients or their guardians.

The following were the exclusion criterias (1) Patients with difficulty in explaining their past and recent motor deficits.

Demographic data, clinical characteristics, and neuroimaging findings were recorded.. The neuroimaging scan was performed on a $1.5 \mathrm{~T}$ MRI scanner (GE Healthcare, Milwaukee, Wisconsin).

\section{Results}

Twenty-two acute cerebral infarction patients (16 men and 6 women) with unusual ipsilateral motor impairment and brain MRI records available for review were found and included in this study. Average age of onset was 63.4 (range 48-83) years.

\section{Clinical presentation}

Ten patients had right side ipsilateral paralysis, 11 patients had left side ipsilateral paralysis and one patient had bilateral paralysis. The most frequent symptom was ipsilateral limb paralysis, which was observed in all cases. The other unusual symptom was central facioplegia (1 case).

Majority of patients with limb paralysis (90.9\%, 20/ 22) presented with mild muscle strength deficits (MRC grading of 4 or more), two patients $(9.1 \%, 2 /$ 22) presented with moderate muscle strength deficits (MRC grading of 3) and no patient presented with severe muscle strength deficits (MRC grading of 2 or less).

Three patients presented with hyperreflexia in paralyzed limbs and four patients presented with hyporeflexia in paralyzed limbs. Five patients presented with pathological reflexes in paralyzed limbs.

The most of the patients $(72.7 \%, 16 / 22)$ had a history of stroke (cerebral infarction in 14 and cerebral hemorrhage in two), and previous strokes were contralateral to the side of the recent stroke in 14 out of 16 patients $(87.5 \%)$. No history of stroke or old lesions were identified in seven patients. Demographics and clinical characteristics of all cases are listed in Table 1.

\section{MRI findings}

Brain MRI was performed in all patients. The interval from onset to performing MRI was less than 15 days in most cases $(19 / 22)$ in our study. The majority of responsible lesions for motor deficits were located in corona $\operatorname{radiate}(n=10,45.5 \%)$, internal capsula $(n=5,22.7 \%)$, pons $(n=4,18.2 \%)$, pedunculus cerebri $(n=1,4.5 \%)$, middle frontal $\operatorname{gyrus}(n=1$, $4.5 \%)$, superior parietal $\operatorname{lobule}(n=1,4.5 \%)$. infract lesions of all cases are likely to involve pyramidal tract. All patient with the history of stroke had obvious old infarct lesions contralateral to neurological deficit in past stroke. No patient was reported to have cerebral malformations, such as arteriovenous malformation, Dandy-Walker malformation orogenesis of the corpus callosum, etc. Neuroimaging findings of all cases are summarized in Table 2 and Figs. 1 and 2.

\section{Discussion}

Unusual ipsilateral motor impairment after a cerebral stroke has rarely been reported. In the present study, we summarized the clinical features of ipsilateral cerebral infarct as small lesions in the MRI findings, a high proportion of hemiparesis, and the history of strokes contralateral to the recent strokes.

In our study, most cases demonstrated small patchy lesions (Fig. 1), and the recent responsible lesions located along pyramidal tract, which is consistent with findings of previous studies [5]. However, only patient 3 shows bilateral hemiparesis due to unilateral stroke, no obvious motor deficits contralateral to infarct were 
Table 1 Clinical profile in cerebral infarction patients with unusual ipsilateral motor impairment

\begin{tabular}{|c|c|c|c|c|c|c|c|c|c|}
\hline \multirow[t]{3}{*}{ No. } & \multicolumn{2}{|l|}{ Past stroke } & \multicolumn{7}{|l|}{ Recent Cl } \\
\hline & \multirow{2}{*}{$\begin{array}{l}\text { Type and } \\
\text { Main } \\
\text { symptoms }\end{array}$} & \multirow{2}{*}{$\begin{array}{l}\text { Interval } \\
\text { between } \\
\text { strokes }\end{array}$} & \multirow{2}{*}{$\begin{array}{l}\text { Side and } \\
\text { type of } \\
\text { paralysis }\end{array}$} & \multicolumn{2}{|c|}{ MRC grading (arm/leg) } & \multicolumn{2}{|c|}{ DTR (arm/leg) } & \multicolumn{2}{|c|}{ Pathological reflex (arm/leg) } \\
\hline & & & & $\overline{\text { Ipsi }}$ & Contr & Ipsi & Contr & Ipsi & Contr \\
\hline 1 & $C l, L P(R)$ & 3 months & $R / L P$ & $4 / 4$ & $5 / 5$ & $++/++$ & $++/++$ & $-1-$ & $-1-$ \\
\hline 2 & - & - & $L / L P$ & $4 / 4$ & $5 / 5$ & $++/++$ & $++/++$ & $-1-$ & $-/-$ \\
\hline 3 & $C l, L P(R)$ & 3 years & $L+R / L P$ & $4 / 4$ & $4 / 4$ & $++/++$ & $++/++$ & $-1-$ & $-/-$ \\
\hline 4 & $\mathrm{CH}, \mathrm{LP}(\mathrm{L})$ & 3 months & $L / L P$ & $4 / 4$ & $5 / 5$ & $++/++$ & $++/++$ & $-1-$ & $-/-$ \\
\hline 5 & $C l, L P(L)$ & 2 years & $L / L P$ & $4 / 4$ & $5 / 5$ & $++/++$ & $++/++$ & $-1-$ & $-/-$ \\
\hline 6 & $C l, L P(R)$ & 1 years & $L / L P$ & $4 / 4$ & $5 / 5$ & $++/++$ & $++/++$ & $-1-$ & $-/-$ \\
\hline 7 & $C l, L P(R)$ & 2 years & $R / L P$ & $4 / 4$ & $5 / 5$ & $++/+++$ & $++/++$ & $-1-$ & $-/-$ \\
\hline 8 & - & - & $R / L P$ & $4 / 4$ & $5 / 5$ & $+/+$ & $++/++$ & $-1-$ & $-/-$ \\
\hline 9 & $\mathrm{Cl}, \mathrm{LP}(\mathrm{R})$ & 1 years & $R / L P$ & $4 / 4$ & $5 / 5$ & $++/++$ & $++/++$ & $-1+$ & $-1-$ \\
\hline 10 & $\mathrm{Cl}, \mathrm{LP}(\mathrm{R})$ & 1 years & $L / L P$ & $4 / 4$ & $4 / 4$ & $++/++$ & $++/++$ & $-1-$ & $-1-$ \\
\hline 11 & - & - & L/LP & $4 / 4$ & $5 / 5$ & $+/+$ & $++/++$ & $-1+$ & $-/-$ \\
\hline 12 & $C l, L P(R)$ & 5 years & $R / L P$ & $4 / 4$ & $5 / 5$ & $+/+$ & $++/++$ & $-1-$ & $-/-$ \\
\hline 13 & $\mathrm{Cl}, \mathrm{LP}(\mathrm{R})$ & 2 years & $R / L P$ & $3 / 4$ & $5 / 5$ & $++/++$ & $++/++$ & $-/+$ & $-/-$ \\
\hline 14 & - & - & $L / L P$ & $4 / 4$ & $5 / 5$ & $++/++$ & $++/++$ & $-1-$ & $-1-$ \\
\hline 15 & $\mathrm{CH}, \mathrm{LP}(\mathrm{L})$ & 3 years & $L / L P$ & $4 / 4$ & $5 / 5$ & $++/++$ & $++/++$ & $-1-$ & $-/-$ \\
\hline 16 & $\mathrm{Cl}, \mathrm{HH}(\mathrm{R})$ & 5 years & $R / L P$ & $4 / 4$ & $5 / 5$ & $++/++$ & $++/++$ & $-1+$ & $-1-$ \\
\hline 17 & $C l, L P(L)$ & 8 years & $L / L P$ & $4 / 4$ & $5 / 5$ & $++/++$ & $+/++$ & $-1-$ & $-/-$ \\
\hline 18 & - & - & $L / L P+C F$ & $4 / 4$ & $5 / 5$ & $++/++$ & $++/++$ & $-1-$ & $-/-$ \\
\hline 19 & - & - & $R / L P$ & $4 / 4$ & $5 / 5$ & $++/++$ & $++/++$ & $-1-$ & $-/-$ \\
\hline 20 & $\mathrm{Cl}, \mathrm{LP}(\mathrm{R})$ & 4 years & $R / L P$ & $4 / 4$ & $5 / 5$ & $+++/++$ & $++/++$ & $-1-$ & $-1-$ \\
\hline 21 & $\mathrm{Cl}, \mathrm{LP}(\mathrm{R})$ & 1 year & $R / L P$ & $3 / 3$ & $5 / 5$ & $+++/+++$ & $++/++$ & $-/+$ & $-/-$ \\
\hline 22 & $C l, L P(L)$ & 3 years & L/LP & $4 / 4$ & $5 / 5$ & $+/+$ & $+/+$ & $-/-$ & $-1-$ \\
\hline
\end{tabular}

Cl cerebral infarction, $C H$ cerebral hemorrhage, $M$ male, $F$ female, $R$ right, $L$ left, $L P$ limb paralysis, CF central facioplegia, $H H$ Homonymous Hemianopia, $M R C$ manual motor power test using Medical Research Council grading (arm/leg), DTR deep tendon reflex, Ipsi ipsilateral side to recent lesion, Contr contralateral side to recent lesion

observed in the other 21 cases. A possible explanation for this phenomenon is that uncrossed and crossed corticospinal tracts (CST) might be located closely but clearly separated, and a small infarct is often asymptomatic, the lesion is so small that the direct damage to CST is limited, only uncrossed corticospinal tract is involved in those cases. If the responsible lesions are more extensive, it may cause bilateral paralysis like patient 3 . Besides that, the physicians may be more concerned about symptoms contralateral to responsible lesions based on common sense and clinical experience thus unusual ipsilateral motor impairment may be neglected. Significant high proportion of mild muscle strength deficits $(90.9 \%, 20 / 22)$ were also observed in the present study. Small lesion and prevailing influence of the lateral CST projection contralateral to recent infarct may limit the deficit of motor function.
Consistent with previous studies $[5,11]$, most patients in our study $(72.7 \%, N=16)$ showed history of stroke and it caused limb paralysis contralateral to responsible lesions. Besides that, previous strokes were contralateral to the side of the recent stroke in 14 out of 16 patients (87.5\%), suggesting that recurrent deficit occurring in the same limb from previous stroke in those cases, and past strokes or brain injury contralateral to recent strokes might be associated with the pathogenesis of motor deficits ipsilateral to recent lesions. In previous study conducted by Weiller, et al. [7], regional cerebral blood flow was significantly increased in specific cortical areas of unaffected hemisphere following recovery from motor strokes; In a case reported by Ago, et al., only left motor cortex was activated by the paretic left hand movement after the first stroke, which suggested that cortical reorganization and intensification of the uncrossed CST in unaffected hemisphere occurred 
Table 2 Neuroimaging finding in cerebral infarction patients with unusual motor impairment

\begin{tabular}{|c|c|c|c|c|}
\hline \multirow[t]{2}{*}{ No. } & \multirow{2}{*}{$\begin{array}{l}\text { Past stroke } \\
\text { Location of lesion }\end{array}$} & \multicolumn{3}{|l|}{ Recent Cl } \\
\hline & & Location of lesion & Malformation of brain & Dominant hemisphere \\
\hline 1 & L BG & $R C R$ & No & $\mathrm{R}$ \\
\hline 2 & - & LPC & No & $\mathrm{R}$ \\
\hline 3 & L Po & $\mathrm{R} F \mathrm{FL}, \mathrm{TL}, \mathrm{PL}$ & No & $\mathrm{R}$ \\
\hline 4 & R T & LCR & No & $\mathrm{R}$ \\
\hline 5 & $R T$ & L Po, Ce & No & $\mathrm{R}$ \\
\hline 6 & L CS & L BG & No & $\mathrm{R}$ \\
\hline 7 & L Po & R BG & No & $\mathrm{R}$ \\
\hline 8 & - & $\mathrm{R} \mathrm{FL}, \mathrm{TL}, \mathrm{PL}, \mathrm{CR}$ & No & $\mathrm{R}$ \\
\hline 9 & $L C R$ & $\mathrm{RCR}$ & No & $\mathrm{R}$ \\
\hline 10 & L CS,PL & L BG & No & $\mathrm{R}$ \\
\hline 11 & - & L GC, OL, PL,BP & No & $\mathrm{R}$ \\
\hline 12 & $L C R$ & $\mathrm{RCR}$ & No & $\mathrm{R}$ \\
\hline 13 & L BG,FL & R Po & No & $\mathrm{R}$ \\
\hline 14 & - & LCR & No & $\mathrm{R}$ \\
\hline 15 & R BG & L BG & No & $\mathrm{R}$ \\
\hline 16 & L OL & $\mathrm{R}$ GC, CR & No & $\mathrm{R}$ \\
\hline 17 & R BG & LCR & No & $\mathrm{R}$ \\
\hline 18 & - & LCR & No & $\mathrm{R}$ \\
\hline 19 & - & R Po & No & $\mathrm{R}$ \\
\hline 20 & LCR & R Po & No & $\mathrm{R}$ \\
\hline 21 & L Po & R BG & No & $\mathrm{R}$ \\
\hline 22 & R FL,PL & L CR FL,PL & No & $\mathrm{R}$ \\
\hline
\end{tabular}

$L$ left, $R$ right, $P O$ pons, $C$ cerebellum, $C R$ corona radiate, $B G$ basal ganglia, $B P$ brachium pontis, $G C$ gyrus cinguli, $C S$ centrum semiovale, $P C$ pedunculus cerebri, $F L$ frontal lobe, $T L$ temporal lobe, $P L$ parietal lobe, $O L$ occipital lobe, $T$ thalamus

in the recovery process [1]. In fact, previous studies have identified cortical reorganization within the motor areas of the unaffected hemisphere related to post-stroke motor recovery [8-10], it might be one of the main mechanisms for unusual ipsilateral stroke.

Seven patients without history of stroke or cerebral injury and two patients whose recent lesions were on the same side as the previous stroke lesions were observed in our study, so that it cannot be explained by cortical reorganization. In the study conducted by Lacroix, et al., the terminals of marked CST were measured in gray matter of spinal cord, about $10 \%$ of CST axons terminating ipsilateral to the cortical origin were observed. Besides that, these axons were found to terminate mainly in close proximity to ipsilateral motor neurons, which demonstrated the substrate for cortical activation of ipsilateral muscle groups [12]. So that impairment of uncrossed CST originating from motor cortex could cause ipsilateral motor dysfunction.
In fact, several previous studies had reported patients without congenital decussation of corticospinal tract, but the lack of crossing fibers of those patients often was associated with congenital malformations, such as horizontal gaze palsy with progressive scoliosis (HGPSS), lissencephaly or Dandy Walker malformations [11, 13-16]. In a literature review of ipsilateral hemiparesis in stroke [5], three patients $(18 \% / n=17)$ showed structural defect, such as HGPSS and corpus callosum agenesis. In contrast, a remarkable finding in our cohort of 22 patients was the absence of congenital malformation. It seems that the proportion of patients with congenital malformations in the cases of ipsilateral stroke may be overestimated.

The corticonuclear tract is one part of the pyramidal tracts, it innervates cranial motor nuclei bilaterally with the exception of the lower part of facial nuclei and cranial nerve XII which are innervated only unilaterally. In present study, we found a case of 


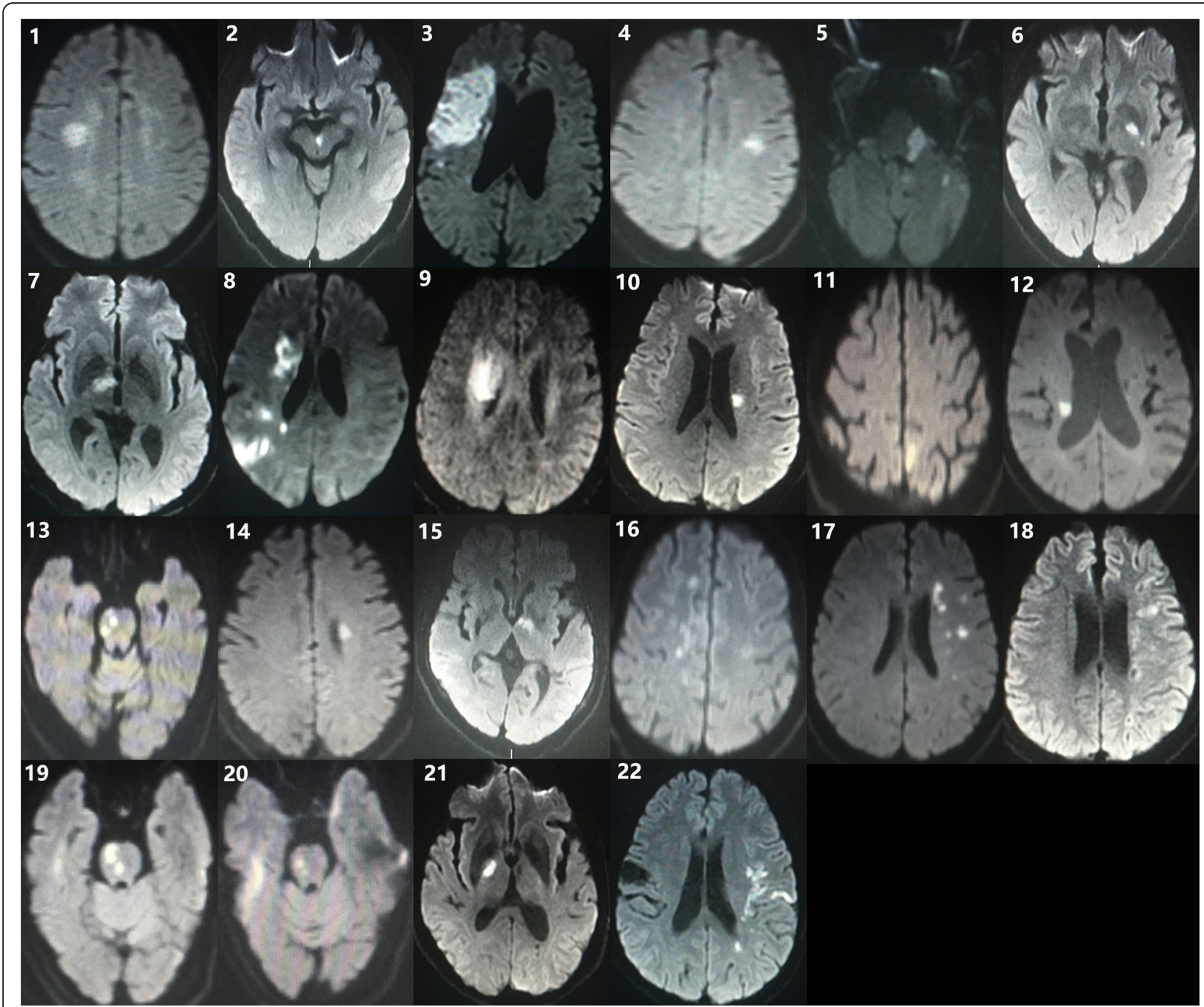

Fig. 1 MRI radiographs of patients show responsible lesions of recent stroke on DWI

supratentorial stroke that show central facioplegia ipsilateral to fresh high T2 and DWI signals in corona radiate and no history of brain injury and congenital malformations were recorded, similar cases have never been reported before. A possible explanation for occurrence of ipsilateral central facioplegia in this case is the presence of uncrossed corticonuclear tract. Alurkar et, al reported an ipsilateral stroke patient without any brain malformation and confirmed that motor cortex on the right controlled ipsilateral side was due to uncrossed pyramidal tracts using Diffusion Tensor Imaging (DTI) tractography [17].

The limitation of our study should be noted. We cannot confirm the type of pyramidal tract accurately without using DTI, which is meaningful for evaluating the path of pyramidal tract. Further studies are required to verify our speculation about the features reported in our cases and to determine the mechanism of cortical reorganization in the occurrence of ipsilateral stroke.

\section{Conclusion}

In the present study, A high proportion of stroke history was observed, which means that history of stroke or cerebral injury plays an important role in the pathogenesis of ipsilateral motor impairment, and cortical reorganization in the unaffected hemisphere may contribute to the compensation of motor function after stroke. Besides that, some cases with first stroke may be due to impairment of ipsilateral uncrossed corticospinal tract. 


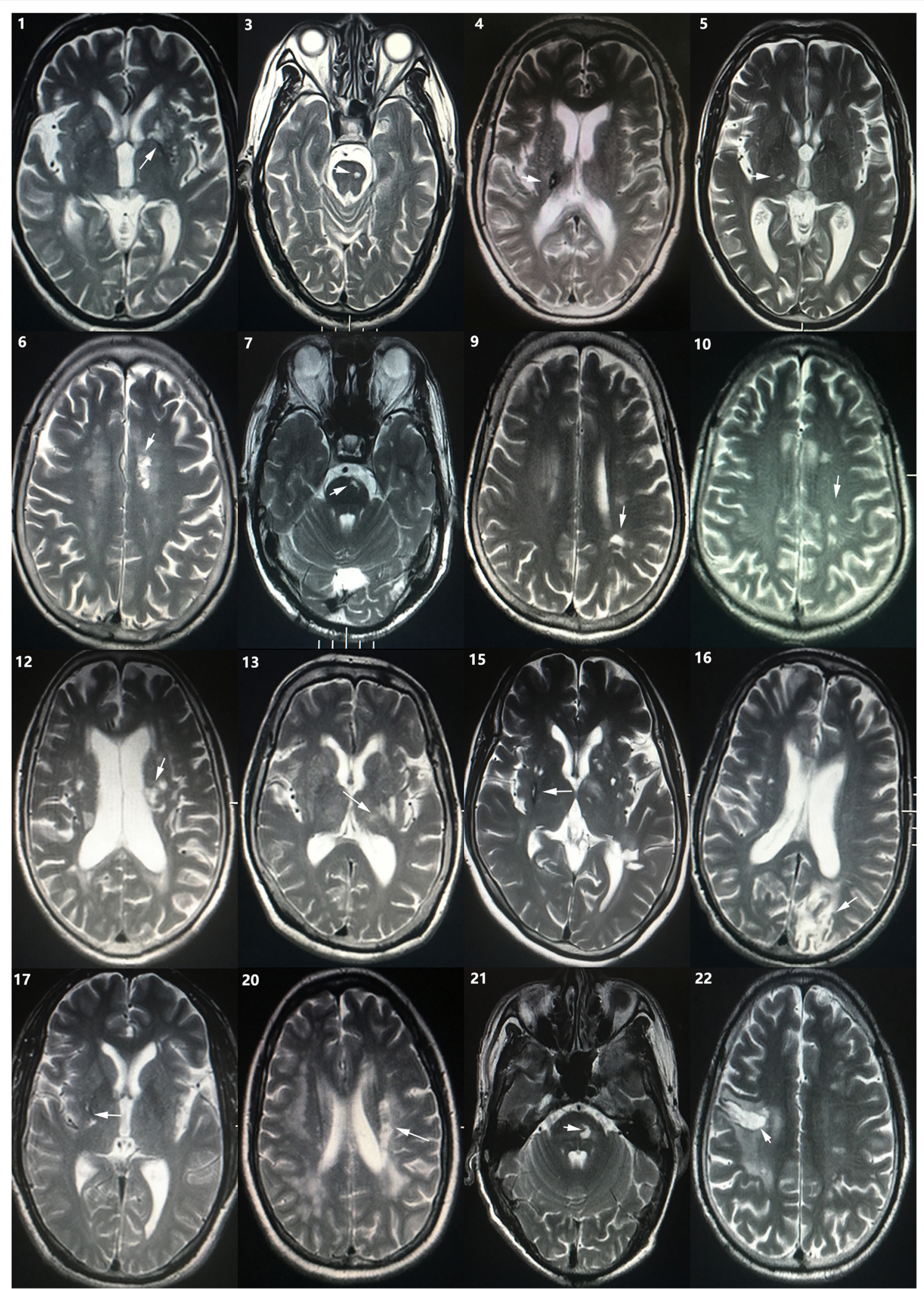

Fig. 2 MRI radiographs of patients show responsible lesions of past stroke on T2-weighted images 


\section{Abbreviations}

CST: Corticospinal tracts; DTI: Diffusion Tensor Imaging; DWI: Diffusionweighted imaging; HGPSS: Horizontal gaze palsy with progressive scoliosis; MRC: Manual motor power test using Medical Research Council grading; MRI: Magnetic resonance imaging

\section{Acknowledgments}

We thank all our colleagues at the Department of Neurology.

\section{Authors' contributions}

All authors had full access to all the data in the study and take responsibility for the integrity of the data and the accuracy of the data analysis.

Conceptualization ZT; Methodology ZT, CZ; Investigation, Formal Analysis, Resources, Visualization, Writing, Original Draft ZT, Writing - Review \& Editing, Supervision FT. All authors read and approved the final manuscript.

\section{Funding}

This study was supported by National key R\&D program of China (2017YFC1310003).

\section{Availability of data and materials}

The data that support the findings of this study are available from the corresponding author via E-mail upon reasonable request.

\section{Ethics approval and consent to participate}

All subjects gave their informed consent prior to their inclusion in the study. This study was approved by the Research Ethics Committee of the Xiangya Hospital.

\section{Consent for publication}

Not applicable.

\section{Competing interests}

The authors declare that they have no competing interests.

Received: 9 July 2019 Accepted: 28 October 2019

Published online: 12 November 2019

\section{References}

1. Ago T, Kitazono T, Ooboshi H, et al. Deterioration of pre-existing hemiparesis brought about by subsequent ipsilateral lacunar infarction. J Neurol Neurosurg Psychiatry. 2003;74(8):1152-3.

2. Hermie L, De Groote J, Geerts B, Vanlangenhove P. Unusual acute ischemic stroke of the ipsilateral middle and posterior cerebral artery territory. Acta Neurol Belg. 2017;117(1):305-7.

3. Ng AS, Sitoh YY, Zhao Y, et al. Ipsilateral stroke in a patient with horizontal gaze palsy with progressive scoliosis and a subcortical infarct. Stroke. 2011; 42(1):e1-3.

4. Kang K, Choi NC. Ipsilateral hemiparesis and spontaneous horizontal nystagmus caused by middle cerebral artery territory infarct in a patient with agenesis of the corpus callosum. Neurol Sci. 2012;33(5):1165-8.

5. Inatomi Y, Nakajima M, Yonehara T, Ando Y. Ipsilateral hemiparesis in ischemic stroke patients. Acta Neurol Scand. 2017;136(1):31-40.

6. Langhorne P, Coupar F, Pollock A. Motor recovery after stroke: a systematic review. Lancet Neurol. 2009:8:741-54.

7. Weiller $C$, Chollet F, Friston K. Functional reorganization of the brain in recovery from striatocapsular infarction in man. Ann Neurol. 1992;31:463-72.

8. Nelles $G$, Spiekermann $G$, Jueptner $M$, et al. Reorganisation of sensory and motor systems in hemiplegic stroke patients. A positron emission tomography study. Stroke. 1999;30:1510-6.

9. Cramer SC, Nelles G, Benson RR, et al. A functional MRI study of subjects recovered from hemiparetic stroke. Stroke. 1997;28:2518-27.

10. Cao Y, D'Olhaberriague L, Vikingstad EM, et al. Pilot study of functional MRI to assess cerebral activation of motor function after poststroke hemiparesis. Stroke. 1998;29:112-22

11. Saada F, Antonios N. Existence of Ipsilateral hemiparesis in ischemic and hemorrhagic stroke: two case reports and review of the literature. Eur Neurol. 2014;71:25-31.

12. Lacroix S, Havton LA, McKay H, et al. Bilateral corticospinal projections arise from each motor cortex in the macaque monkey: a quantitative study. $J$ Comp Neurol. 2004;473(2):147-61.
13. Lagger RL. Failure of pyramidal tract decussation in the Dandy-Walker syndrome. Report of two cases. J Neurosurg. 1979;50:382-7.

14. Nardelli E, Vio M, Ghersini L, et al. Mobius-like syndrome due to multiple cerebral abnormalities including hypoplasia of the descending tracts. A case report. J Neurol. 1982;227:11-9.

15. Roessmann U, Hori A. Agyria (lissencephaly) with anomalous pyramidal crossing. Case report and review of literature. J Neurol Sci. 1985;69:357-64.

16. Amoiridis G, Tzagournissakis M, Christodoulou P, et al. Patients with horizontal gaze palsy and progressive scoliosis due to $\mathrm{ROBO} 3 \mathrm{E} 319 \mathrm{~K}$ mutation have both uncrossed and crossed central nervous system pathways and perform normally on neuropsychological testing. J Neuro Neurosurg Psychiatry. 2006;77:1047-53.

17. Alurkar A, Sudha P, Karanam L, Atre A, et al. Ipsilateral stroke with uncrossed pyramidal tracts and underlying right internal carotid artery stenosis treated with percutaneous transluminal angioplasty and stenting. A rare case report and review of the literature. Neuroradiol J. 2012;25(2):237-42.

\section{Publisher's Note}

Springer Nature remains neutral with regard to jurisdictional claims in published maps and institutional affiliations.
Ready to submit your research? Choose BMC and benefit from:

- fast, convenient online submission

- thorough peer review by experienced researchers in your field

- rapid publication on acceptance

- support for research data, including large and complex data types

- gold Open Access which fosters wider collaboration and increased citations

- maximum visibility for your research: over $100 \mathrm{M}$ website views per year

At BMC, research is always in progress.

Learn more biomedcentral.com/submissions 